\title{
Electroanalytical Investigation of p-nitrophenol with Dual Electroactive Groups on a Reduced Graphene Oxide Modified Glassy Carbon Electrode
}

\author{
Honghong Rao ${ }^{l, *}$, Weiming Guo ${ }^{1}$, Huihui Hou ${ }^{2}, H u i$ Wang $^{2}$, Bo Yin ${ }^{2}$, Zhonghua Xue $e^{2}$ and Guohu Zhao ${ }^{l}$ \\ ${ }^{1}$ College of Chemistry \& Environmental Engineering, Lanzhou City University, Lanzhou, 730070, P. \\ R. China. \\ ${ }^{2}$ Key Laboratory of Bioelectrochemistry \& Environmental Analysis of Gansu Province, College of \\ Chemistry \& Chemical Engineering, Northwest Normal University, Lanzhou, 730070, P. R. China. \\ *E-mail: rhhlab@hotmail.com, $\underline{\text { rhh@nwnu.edu.cn }}$
}

doi: $10.20964 / 2017.02 .39$

Received: 7 November 2016 / Accepted: 15 December 2016 / Published: 30 December 2016

\begin{abstract}
Developing high selective and excellent sensitive electrochemical sensor for electrochemical active species with dual and multiple electroactive groups is very important in various analytical purposes. Here, on the basis of highly sensitive material of electrochemical reduced graphene oxide films modified glassy carbon electrode, the comparative study on the electrochemical sensing of $\mathrm{p}$ nitrophenol (PNP) based on different current response signals offered by the reduction and oxidation process associated with nitro group and phenol group on PNP molecule was successfully demonstrated. By using cyclic voltammetry and chronoamperometry technique, a significant difference on the electrocatalytic and electrochemical detecting between nitro and phenol group of PNP molecule was pointed out. As a result, a remarkably apparent rate constant $\left(\kappa, 6.79 \mathrm{M}^{-1} \mathrm{~s}^{-1}\right)$ and a lower detection limit $\left(0.55 \mu \mathrm{M} \mathrm{L}^{-1}\right)$ by electrochemical reduction process of nitro group was demonstrated, which strongly supporting the fact that the electroactive nitro group of PNP is more appropriate than the phenol group for the construction of sensitive electrochemical sensor.
\end{abstract}

Keywords: Electrochemical sensing; P-nitrophenol; Electrochemically reduced graphene oxide; Dual electroactive molecule; Glassy carbon electrode

\section{$\underline{\text { FULL TEXT }}$}

(C) 2017 The Authors. Published by ESG (www.electrochemsci.org). This article is an open access article distributed under the terms and conditions of the Creative Commons Attribution license (http://creativecommons.org/licenses/by/4.0/). 